\title{
ANÁLISE DA GESTÁO DA VERBA DO PDDE: UMA REVISÃO TEÓRICA
}

Sérgio Luis de Jesus ${ }^{1}$

Wânia Maria de Araújo²

\section{RESUMO}

O artigo aborda considerações teóricas sobre o entendimento da gestão da verba do PDDE, buscando identificar formas de democratizar o uso dessa verba com vistas à qualidade de vida da comunidade escolar. Compreende-se que a gestão escolar é um cargo de caráter político no qual o gestor tem como obrigação gerir recursos públicos para o bem da escola e da comunidade escolar. Assim, com uma maior participação dos membros da comunidade escolar, esta verba poderia se tornar uma ferramenta de desenvolvimento local. Os resultados a partir da pesquisa bibliográfica, possibilitou analisar o processo de gasto da verba do PDDE bem como a relação do seu do seu uso e suas possíveis relações com a gestão social, com vistas no desenvolvimento local.

Palavras chaves: Recurso Público. Gestão Social e Escolar. Participação.

\section{PDDE FUNDING MANAGEMENT ANALYSIS: A THEORETICAL REVIEW}

\section{ABSTRACT}

The article discusses theoretical considerations about the understanding of the management of PDDE funding, seeking to identify ways to democratize the use of this money with a view to the quality of life of the school community. It is understood that school management is a position of political character in which the manager has the obligation to manage public resources for the good of the school and the school community. Thus, with greater participation of members of the school community, this money could become a tool for local development. The results from the bibliographic research allowed us to analyze the PDDE spending process as well as the relation between its use and its possible relations with social management, with a view to local development.

Keywords: Public Appeal. Social and School Management. Participation.

\footnotetext{
${ }^{11}$ Possui graduação em Ciências Biológicas pelo Centro Universitário Metodista Izabela Hendrix Email-perfusaouna@gmail.com

${ }^{2}$ Doutorado em Ciências Sociais pela Pontifícia Universidade Católica de Minas Gerais (PUC/MINAS). Professora do Programa de Pós-Graduação em Gestão Social, Educação e Desenvolvimento Local no Centro Universitário UNA. Email wania.maria@yahoo.com.br
} 


\section{INTRODUÇÃo}

$\mathrm{Na}$ área da educação o grande desafio enfrentado pelo gestor escolar, é de lidar com um contexto político, econômico, cultural e organizacional, muitas vezes adverso ao desenvolvimento das potencialidades dos discentes e docentes da instituição onde trabalha.

A comunidade escolar é constituída a partir da união dos seus representantes em prol do acesso efetivo à educação das crianças e adolescentes que frequentam a escola, logo, as decisões escolares devem ser feitas coletivamente, estabelecendo assim, um ambiente democrático.

Dessa forma, uma gestão democrática vem contemplar os anseios por uma educação de qualidade e para fortalecer o sentimento de pertencimento da comunidade escolar. Ao abrir-se para a participação da comunidade escolar, fomentando os conselhos e grêmios escolares, o gestor, pautado no projeto políticopedagógico da escola, busca uma melhor qualidade de vida para a comunidade.

Configura-se assim, o problema que deu origem a esta pesquisa: em que medida o PDDE tem contribuído não só para uma gestão responsável do gasto público, mas também para estabelecer práticas democráticas na gestão escolar? Dessa forma, o propósito desta pesquisa é analisar o processo de gasto da verba do PDDE bem como a relação do seu do seu uso e suas possíveis relações com a gestão social, com vistas no desenvolvimento local.

Diante do referencial teórico abordado foi possível observar que uma gestão democrática busca incessantemente uma maior participação da comunidade escolar nos processos decisórios dentro da instituição, no qual o gestor tem como obrigação gerir recursos para o bem da escola e da comunidade escolar.

\subsection{Comunidade Escolar}

O conceito de comunidade escolar agrupa professores, funcionários, pais e alunos. No entanto, pode ser observada alguma variação no que diz respeito à composição da comunidade de uma instituição de ensino, entre diferentes 
documentos de políticas e programas educacionais ou textos legais a eles relativos.

Em certos casos, associações de bairro, sindicatos, entidades comunitárias de uma forma geral são incorporadas, desde que atuantes no bairro em que a escola esteja situada. Essa poderia ser considerada uma visão mais ampla do conceito (TEIXEIRA, 2000).

A fim de obter uma compreensão apurada do termo é preciso retomar ao primeiro conceito de comunidade, especialmente para a Sociologia. Para o sociólogo alemão Ferdinand Tönnies (1979), comunidade significa vida real e orgânica.

Nesse sentido, Lemos (2009) conceitua comunidade da seguinte maneira:

\begin{abstract}
Há um pressuposto que rege a comunidade: a perfeita unidade das vontades humanas como estado originário ou natural. As relações que compõem a comunidade são, para o autor, relações de sangue, de lugar e de espírito, derivadas do parentesco (casa), da vizinhança (convivência na aldeia) e da amizade (identidade e semelhança nas profissões). $\mathrm{Na}$ comunidade é muito importante a "compreensão" (consenso), que é um modo associativo de sentir comum e recíproco. Esta compreensão implica a posse e o desfrute de bens comuns, amigos e inimigos comuns, e também a vontade de proteção e defesa recíproca (LEMOS, 2009, p. 203).
\end{abstract}

Conforme a discussão dos autores, o termo comunidade não é um termo engessado e pode ser ressignificado, demonstrando que essa não é uma relação simples, homogênea, baseada em alguma tradição, ocupação de uma mesma área ou laços de consanguinidade, e sim uma relação complexa, heterogênea e passível de ser construída entre aqueles que estejam dispostos a dela participar.

Dessa maneira, pode-se dizer que o processo de gestão democrática da educação amplia as responsabilidades, os espaços de decisão nas escolas e o próprio conceito de comunidade ao implementar mudanças na sua prática cotidiana, resultando em novas e diferenciadas formas de gestão escolar (PACHECO, 2007).

\title{
1.2 Conselhos Escolares
}

De acordo com o Ministério da Educação (MEC) o Conselho Escolar se constitui como órgão colegiado, com representatividade de todos os setores da comunidade escolar, que tem por objetivo fortalecer e ampliar a participação da comunidade, família, alunos, professores e funcionários no bom funcionamento da escola. Isso contribui tanto para a organização e aplicação de recursos, como 
também para a organização de planos, metas e projetos escolares, garantindo assim uma gestão democrática do ensino (BRASIL/MEC, 2004). Dessa forma, é importante destacar primeiramente os aspectos que envolvem a gestão democrática. Nos documentos oficiais, a visão do MEC é assim enunciada:

\begin{abstract}
A gestão democrática implica a efetivação de novos processos de organização e gestão, baseados em uma dinâmica que favoreça os processos coletivos e participativos de decisão. [...] A participação pode ser entendida, portanto, como processo complexo que envolve vários cenários e múltiplas possibilidades de organização. Ou seja, não existe apenas uma forma ou lógica de participação: há dinâmicas que se caracterizam por um processo de pequena participação e outras que se caracterizam por efetivar processos em que se busca compartilhar as ações e as tomadas de decisão por meio do trabalho coletivo, envolvendo os diferentes segmentos da comunidade escolar (BRASIL/MEC, 2004, p. 13-14).
\end{abstract}

A Constituição Federal - CF - de 1988 em seu Artigo 206 estabelece os princípios sobre os quais o ensino deve ser ministrado no país, com destaque para a sua gestão democrática. A Lei de Diretrizes e Bases da Educação Nacional LDBEN de 1996 em seus Artigos 14 e 15 garantem a participação das comunidades escolares e locais em conselhos escolares, enquanto princípios de gestão democrática, ressaltando que cabe aos sistemas de ensino, assegurar às unidades escolares públicas de educação básica, progressivos graus de autonomia pedagógica, administrativa e financeira.

O diretor escolar atua como coordenador na execução das decisões do conselho e como articulador das ações de todos os segmentos. Ele pode ser também o próprio presidente do Conselho Escolar, já que isso fica a critério de cada regulamento.

Uma vez eleito, a atuação dos Conselhos Escolares se divide entre as funções deliberativas, consultivas, fiscalizadoras e mobilizadoras. As funções deliberativas dizem respeito às decisões sobre o Projeto Político-Pedagógico entre outros assuntos da escola. A função consultiva refere-se à emissão de pareceres para dirimir as dúvidas no âmbito pedagógico, administrativo e financeiro. A função fiscalizadora requer o acompanhamento e fiscalização da gestão pedagógica, administrativa e financeira da unidade escolar. Por fim, a função mobilizadora consiste na busca de apoio da comunidade escolar e local quanto à melhoria da 


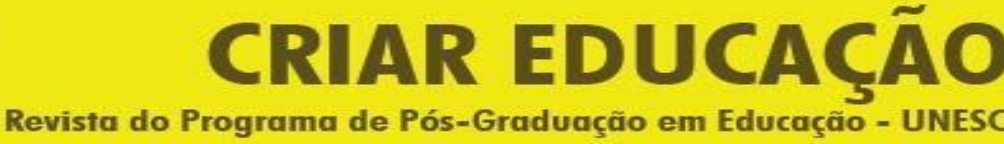

qualidade do ensino, acesso, permanência e aprendizagem dos estudantes (NAVARRO, 2004).

\subsection{Projeto Político-Pedagógico}

O Projeto Político-Pedagógico - PPP - é um documento no qual estão registradas as ações e projetos de uma determinada comunidade escolar, sendo auxiliado por professores, coordenação escolar, alunos e familiares. Para isso desenvolvem atividades pedagógicas que auxiliam no processo de ensinoaprendizagem (VAGULA et al., 2014).

Charlot (2004) refere-se ao projeto pedagógico não apenas como "[...] um programa de ações de organização, de gestão, mas remete a valores fundamentais [...] a um projeto de homem e de sociedade" (CHARLOT, 2004, p. 24). Nesse sentido é possível dizer que o PPP carrega a marca identitária de uma comunidade educativa.

Segundo Ferreira (2009, p. 1), "fazer o PPP implica planejamento de todas as atividades no âmbito escolar, execução das ações previstas, avaliação do processo e retomada. Isso somente é possível se instituída a prática do registro e da reflexão sobre ele". Sua importância está no desenvolvimento de uma instituição de ensino que almeja uma educação operativa e de qualidade. Dessa forma, torna-se uma rota flexível o bastante para se adaptar às necessidades dos alunos. "[...] a sua construção deve conter os temas como: missão, público-alvo, dados sobre a aprendizagem, relação com as famílias, recursos, diretrizes pedagógicas e plano de ação" (LOURENÇO; SILVA, 2015, p. 1).

Nesse sentido Veiga (2003) ainda enfatiza:

Inovação e projeto político-pedagógico estão articulados, integrando o processo com o produto porque o resultado final não é só um processo consolidado de inovação metodológica no interior de um projeto políticopedagógico construído, desenvolvido e avaliado coletivamente, mas é um produto inovador que provocará também rupturas epistemológicas. Não podemos separar processo de produto (VEIGA, 2003, p.273).

O PPP, se de fato concebido coletivamente e for, ao mesmo tempo, constituinte de uma comunidade educativa, pode ser capaz de acolher novas 
orientações curriculares sem perder sua identidade, uma vez que tenha como característica a ousadia de experimentar e inovar.

\subsection{Programa Dinheiro Direto na Escola (PDDE)}

A descentralização no campo da educação não é um tema novo, porém, é crescente o interesse na sua abordagem. O processo de descentralização teve início com a Constituição Federal de 1988, no que tange ao financiamento da educação no contexto da Reforma Administrativa do Estado.

A descentralização ganhou impulso e conotação específica no que diz respeito ao financiamento da educação no contexto da Reforma Administrativa do Estado, quando a descentralização das funções administrativas passou a exigir o respectivo aporte financeiro para a manutenção e o custeio das despesas nas escolas, processo do qual derivou a criação do PDDE (REZENDE, 2005).

O PDDE teve início em 1995 no governo de Fernando Henrique Cardoso, inicialmente denominado de Programa de Manutenção e Desenvolvimento do Ensino Fundamental - PMDE. Por força da Medida Provisória no 1.784, de 14 de dezembro de 1998 o PMDE passou a ser denominado Programa Dinheiro Direto na Escola - PDDE (BRASIL/FNDE, 2009).

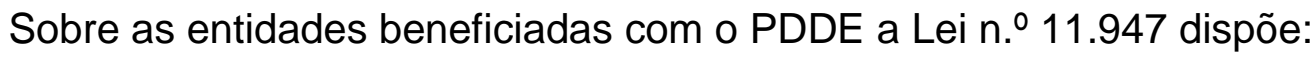

Art. 22. O Programa Dinheiro Direto na Escola - PDDE, com o objetivo de prestar assistência financeira, em caráter suplementar, às escolas públicas da educação básica das redes estaduais, municipais e do Distrito Federal, às escolas de educação especial qualificadas como beneficentes de assistência social ou de atendimento direto e gratuito ao público, às escolas mantidas por entidades de tais gêneros e aos polos presenciais do sistema Universidade Aberta do Brasil - UAB que ofertem programas de formação inicial ou continuada a profissionais da educação básica (BRASIL/FNDE, 2009).

O programa foi criado com o propósito de prestar assistência financeira, em caráter suplementar, às escolas públicas municipais, estaduais e do Distrito Federal, desde que registradas no Conselho Nacional de Assistência Social - CNAS. A Resolução FNDE/CD, n 10, de 27 de março de 2004, inclui repasse de verba as instituições privadas de educação especial; indígena; privadas de educação 

TEIXEIRA, 2015).

O recurso do PDDE é repassado para as escolas com mais de 50 alunos matriculados, uma vez ao ano, em uma conta criada pelo Fundo Nacional de Desenvolvimento da Educação (FNDE) no nome da associação de pais, Mestres e Funcionários (APMF) de cada escola. O valor repassado é calculado com base no número de alunos matriculados, de acordo com o censo escolar do ano anterior (OLIVEIRA; LIMA, 2015).

Para que a escola seja contemplada, o requisito básico é a existência de uma unidade executora - UEx. Esta entidade tem como função receber, administrar, executar e prestar conta dos recursos advindos de órgãos federais, estaduais, municipais e privados, doados ou provenientes de campanhas escolares.

A Resolução no 17 de 19 de abril de 2011 da Constituição Federal de 1988, apresentam as despesas que não podem receber suprimento do PDDE, sendo:

\footnotetext{
$\S 1$ 1 É vedada a aplicação dos recursos do PDDE em:

I - Implementação de outras ações que estejam sendo objeto de financiamento pelo Fundo Nacional de Desenvolvimento da Educação (FNDE), à exceção das agregadas ao programa;

II - Gastos com pessoal;

III - pagamento, a qualquer título, a militar ou a servidor público, da ativa, ou a empregado de empresa pública ou de sociedade de economia mista por serviços prestados, inclusive consultoria, assistência técnica ou assemelhados;

IV - Cobertura de despesas com tarifas bancárias, à exceção das que porventura incidam na efetivação de transferências eletrônicas de disponibilidade para pagamento de dispêndios relacionados com as finalidades do programa, em conformidade com o $\S 5^{\circ}$ do art. 12; e

$V$ - Dispêndios com tributos federais, distritais, estaduais e municipais quando não incidentes sobre os bens adquiridos ou produzidos e os serviços contratados para a consecução dos objetivos do programa (CONSTITUIÇÃO FEDERAL,1988, CAP. III Art. 4º).
}

Após receber a verba e a utilização, as unidades executoras deverão prestar contas, atendendo as seguintes normas definidas pelo FNDE, e os valores do PDDE são repassados para as escolas de acordo com suas especificidades e, principalmente, esta distribuição tem como base o número de alunos matriculados inscritos no censo escolar do INEP do ano anterior ao do repasse. São contempladas com a verba do PDDE, na grande maioria as escolas públicas sendo elas das áreas urbana ou rural. As escolas da rede privada podem receber 0 repasse da verba quando contempla a educação especial. Assim, cada escola tem Criar Educação, Criciúma, v. 8, no1, jan/jul 2019.- PPGE - UNESC 
de acordo com o enquadramento (conforme tabela 1) os valores prévios da verba e a possibilidade de um melhor planejamento desta verba (BRASIL/FNDE, 2013).

No ano de 2013, com o intuito de minimizar as dificuldades identificadas e potencializar tais resultados, foram implementadas inovações na gestão do PDDE, dando destaque à desburocratização da adesão das entidades beneficiárias ao programa. Para dar mais agilidade na transferência dos recursos financeiros, as Secretarias Estaduais de Educação e Prefeituras Municipais que já tinham aderido ao PDDE em anos anteriores, por meio do sistema PDDE web, foram dispensadas de realizar esse procedimento anualmente (BRASIL/FNDE, 2013).

Em meio as transformações econômicas, políticas e sociais que vêm ocorrendo no mundo atual, especialmente na educação, o PDDE, como um dos principais elementos da descentralização da gestão financeira para a escola, tem implicações diretas para gestão educacional, especificamente à democratização da gestão da escola, à relação público e privado e à relação entre descentralização e centralização (ADRIÃO; PERONI, 2007).

\subsection{Gestão Social e Desenvolvimento Local}

Desde a última década do século XX e até hoje no Brasil, a gestão social e o desenvolvimento local têm sido assuntos em voga. As inquietações e discussões a esse respeito ressaltaram a necessidade de aprimoramento das práticas sociais e de ações objetivas dos projetos sociais (GRAMSCI, 1999). Segundo Tenório (1997; 1998), a gestão social é o conjunto de processos sociais no qual a ação gerencial se desenvolve por meio de uma ação negociada entre seus atores, perdendo o caráter burocrático em função da relação direta entre o processo administrativo e a múltipla participação social e política.

Carvalho (1999) corrobora com Tenório $(1997 ; 1998)$ quando ressalta que:

Se trata da gestão das ações sociais públicas, sendo que a gestão do social é a gestão das demandas e necessidades dos cidadãos. E as respostas a essas demandas e necessidades são as políticas sociais, os programas e projetos sociais. A gestão social tem um compromisso, com a sociedade e com os cidadãos, de assegurar por meio das políticas e programas públicos o acesso efetivo aos bens, serviços e riquezas societárias. Por isso mesmo, precisa ser estratégica e consequente (CARVALHO, 1999, p.28). 
Nesse sentido, é possível dizer que para a construção e ampliação do poder local, é necessária a participação dos cidadãos, de forma compartilhada e cooperativa para que haja discussões em todos os níveis hierárquicos, nas diversas questões sociais, pois, o compartilhamento do poder dá ao cidadão a capacidade de influir sobre o uso de determinado recurso, por exemplo, visando qualidade de vida e desenvolvimento humano (CAMARGOS, 2016).

A respeito do desenvolvimento local, discorrer sobre o tema seria abordar inúmeros conceitos. Entretanto, um projeto de desenvolvimento local, independentemente de seu conceito e método, necessita de uma gestão e tem uma estreita vinculação com os processos educativos que acontecem em dada comunidade (MARTIN; THOMAZI, 2014).

Segundo Senhoras; Takeuchi (2005), o local define onde acontece a relação para o estabelecimento das ações, mas, essas ações não podem ficar confinadas, pois, o desenvolvimento sustentável implica uma inclusão social, que ultrapassa o local. Daí decorre uma relação clara entre o desenvolvimento local e a gestão social. O fio que une a gestão social e o desenvolvimento local é a comunidade que tanto atua como agente condutora da mudança, como sendo beneficiária

Desenvolvimento local pode ser entendido como um processo de transformação que envolve o ser humano como "o principal beneficiário dessa mudança, numa perspectiva de melhoria da qualidade de vida de uma coletividade ou grupo de pessoas que fazem parte de uma comunidade" (CASTILHO; ARENHARDT; LE BOURLEGAT, 2009, p. 1). O fio que une a gestão social e o desenvolvimento local é a comunidade que tanto atua como agente condutora da mudança, como sendo beneficiária.

Diante das reflexões acerca da gestão social e desenvolvimento local, é possível pontuar que, a partir de uma gestão escolar democrática centrada na participação e compromisso de todos os atores, vinculados ao planejamento e à organização pedagógica, principalmente dos objetivos educacionais e planejamentos estratégicos das escolas como o PPP, poderá consolidar ações interativas, baseadas na ética, na valorização dos profissionais, com flexibilidade, compromisso e responsabilidade no que tange, por exemplo, ao uso da verba do PDDE. 


\section{METODOLOGIA}

Segundo Minayo (2009), a metodologia de uma pesquisa configura-se em uma linha de pensamento, orientada para a busca da solução de um problema, considerando a literatura e a prática exercida na abordagem da realidade.

Este estudo constitui uma revisão bibliográfica de caráter analítico a respeito da gestão da verba do PDDE, suas características de inovação social, de forma a contribuir com desenvolvimento do local no qual a escola se insere.

\section{RESULTADOS}

As pesquisas bibliográficas demonstraram que é imprescindível a participação efetiva de todos os membros da comunidade escolar em todos os processos decisórios do uso da verba do PDDE, com a preocupação sistemática da qualidade de vida coletiva e do desenvolvimento local. Assim, defende-se que com uma maior participação dos membros da comunidade escolar, esta verba poderia se tornar uma ferramenta de desenvolvimento local.

\section{CONSIDERAÇÕES FINAIS}

A autonomia do gestor pode levar a decisões arbitrárias se não houver a participação da comunidade. Diante disto, faz-se relevante discorrer sobre a forma como este recurso é gasto, enfatizando a necessidade de que seu uso seja pensado coletivamente, de forma dialógica. Uma sistematização da prática de uso da verba pública com a presença dos diversos atores da comunidade escolar, de uma maneira que favoreça e concretize a cidadania e o empoderamento dos atores do território.

A gestão democrática é um processo complexo, mas possível, que depende fundamentalmente da elaboração do projeto político-pedagógico, que é o grande articulador do processo democrático da escola, quando o gestor mobiliza a comunidade escolar para que se comprometa e participe dos processos decisórios e pedagógicos da escola.

É possível dizer também, que a gestão democrática não é apenas um alicerce para conquista da autonomia e da construção de forma coletiva de administrar, mas Criar Educação, Criciúma, v. 8, no1, jan/jul 2019.- PPGE - UNESC 
também é, fundamentalmente, uma necessidade e, como tal, deveria ser o objetivo comum de todas as escolas.

\section{REFERÊNCIAS}

ADRIÃO, T.; PERONI, V. Implicações do Programa Dinheiro Direto na Escola para a gestão da escola pública. Educ. Soc., Campinas, vol.28, n.98, p. 253-267, jan./abr. 2007. Disponível em:

$<$ http://www.scielo.br/scielo.php?script=sci_arttext\&pid=S010173302007000100013\& Ing=pt\&nrm=iso>. Acesso em 08 abr. 2018.

BRASIL. Constituição da República Federativa do Brasil: texto constitucional promulgado em 5 de outubro de 1988. Disponível em:

<http://bd.camara.gov.br/bd/handle/bdcamara/15261>. Acesso em 5 de dez. 2017.

Fundo Nacional de Desenvolvimento da Educação (FNDE). Lei 11.947, de 16 de junho de 2009. Dispõe sobre o atendimento da alimentação escolar e do Programa Dinheiro Direto na Escola aos alunos da educação básica. Disponível em: $<$ https://www.fnde.gov.br/fndelegis/action/UrlPublicasAction.php?acao=getAtoPublic o\&sgl_tipo=LEI\&num_ato $=00011947 \&$ seq_ato $=000 \& v i r \_a n o=2009 \& s g l \_o r g a o=N I>. A$ cesso em: 4 de dez. 2017.

. Fundo Nacional de Desenvolvimento da Educação (FNDE) Programa Dinheiro Direto na Escola (PDDE) - Brasília, DF, 2013. Disponível em: < http://www.fnde.gov.br/programas/pdde/sobre-o-plano-ou-programa/funcionamento>. Acesso em: 12 dez. de 2017.

Lei no 9.394, de 20 de dezembro de 1996. Estabelece as Diretrizes e Bases da Educação Nacional (LDBEN). Disponível em: <http://www.planalto.gov.br/Ccivil_03/leis/L9394.htm>.Acesso em 18 de nov. 2017.

Ministério da Educação. Secretaria de Educação Básica. Conselho Escolar, gestão democrática da educação e escolha do diretor. Brasília - DF, 2004. Disponível em: <http://portal.mec.gov.br/seb/arquivos/pdf/Consescol/ce _cad5.pdf>. Acesso em: 20 nov. 2017.

CAMARGOS, Daniela Aguilar. Descentralização, poder local e participação social: perspectivas para construção de uma nova cultura política. III Colóquio de ética, filosofia política e direito. UNISC 2016. Disponível em:

<http://docplayer.com.br/69661033-Descentralizacao-poder-local-e-participacaosocial-perspectivas-para-a-construcao-de-uma-nova-cultura-politica.html>. Acesso em 3 de mar. 2018.

CARVALHO, Maria do Carmo Brant de. Gestão Social: alguns apontamentos para o debate. In: Gestão Social - uma questão em debate. São Paulo: EDUC-IEE, 1999. 
CASTILHO Maria Augusta de.; ARENHARDT, Mauro Mallmann.; LE BOURLEGAT, Cleonice Alexandre. Cultura e identidade: os desafios para o desenvolvimento local no assentamento Aroeira, Chapadão do Sul, MS. Interações, v. 10, n. 2, 2009. p. 159-169. Disponível em: <http://www.scielo.br/pdf/inter/v10n2/v10n2a04>. Acesso em 20 de dez. de 2017.

CHARLOT, B. Projeto político e projeto pedagógico. In: MOLL, J. (org.). Ciclos na escola, tempos na vida: criando possibilidades. Porto Alegre: ArtMed, 2004. p. 2326.

FERREIRA, I. Projeto político-pedagógico. 2009. Disponível em:<http://www,sed.sc.gov.br/secretaria/ppp>. Acesso em 3 nov.2017.

GRAMSCI, Antônio. Cadernos do cárcere. Rio de Janeiro: Civilização Brasileira, v. $1,1999$.

LEMOS, Carolina Teles. A (re) construção do conceito de comunidade como um desafio à sociologia da religião. Estudos de Religião, v. 23, n. 36, 201-216, jan./jun. 2009. Disponível em:

<file://C:/Users/CARDOSO/AppData/Local/Packages/Microsoft.MicrosoftEdge_8wek yb3d8bbwe/TempState/Downloads/881-1120-1-PB.pdf>. Acesso em 4 de mar. de 2018.

LOURENÇO, Linesanio de Souza.; SILVA, Deinne Airles da. A importância do projeto político pedagógico para organização escolar. Cederj/Fundação Cecierj ISSN: 1984-6290B3 EM ENSINO - QUALIS, CAPES. 2015. Disponível em: $<$ http://educacaopublica.cederj.edu.br/revista/artigos/a-importancia-do-projetopolitico-pedagogico-para-a-organizacao-escolar>. Acesso em 2 de mar. 2018.

MARTINS, Natham Ribeiro.; THOMAZI, Áurea Regina Guimarães. Gestão social e desenvolvimento local: princípios, conceitos e possíveis relações com o Terceiro Setor. Revista Tecer, v7, n12, p.15-22.2014. Disponível em:

<http://www.bibliotekevirtual.org/index.php/2013-02-07-03-02-35/2013-02-07-03-0311/296-rt/v07n12/2336-v07n12a02.html>. Acesso em 2 de mar. de 2018.

MINAYO, M. C. S. Pesquisa social: teoria, método e criatividade. Rio de Janeiro: Vozes, 2009.

NAVARRO, I.P. et al. Conselhos escolares: democratização da escola e construção da cidadania. Brasília: MEC/SEB, 2004.

OLIVEIRA, Miriane Soares.; LIMA, Michelle Fernandes. Um estudo sobre o programa direto na escola PDDE In: Grupo de Trabalho - Políticas Públicas, Avaliação e Gestão da Educação Básica, Campinas, 2015.

OLIVEIRA, Rita de Cássia.; TEIXEIRA, Beatriz de Bastos. Descentralização e gestão do ensino nos programas PDE Escola e Mais Educação. RBPAE - v. 31, n. 2, 312 maios/ago. 2015. p. 293. Disponível em: 
<http://seer.ufrgs.br/index.php/rbpae/article/viewFile/54557/36504>. Acesso em 4 de mar. de 2018.

PACHECO, Neiva Maria da Rosa. Gestão democrática e relação escola e comunidade: um estudo sobre a experiência do Morro da Cruz, Florianópolis, SC. Dissertação (Mestrado) - Universidade do Vale do Rio dos Sinos - UNISINO. Centro de Ciências Humanas/ Programa de Pós-Graduação em Educação. 2007.p. 219.

SENHORAS, Elói.; TAKEUCHI, Kelly Pereira. A Gestão pública entre a competição e a solidariedade: desvendando as estratégias do desenvolvimento local. Anais. Segundo Simpósio de Excelência em Gestão e tecnologia - SEGeT - 2005.

TEIXEIRA, B. de B. Por uma escola democrática: colegiado, currículo e comunidade. Tese (Doutorado) - Faculdade de Educação. Universidade de São Paulo, São Paulo, 2000. p. 334.

TENÓRIO, Fernando (org.). Gestão de ONGs: principais funções gerenciais. Rio de Janeiro: Fundação Getúlio Vargas, 1997.

Gestão social: uma perspectiva conceitual. Revista de Administração Pública, v.32, № 5, p.7-23, 1998. Disponível em:

<http://bibliotecadigital.fgv.br/ojs/index.php/rap/article/view/7754/6346>. Acesso em 7 de dez. de 2017.

TÖNNIES, F. Comunidad y asociación. Barcelona: Península, 1979.

VAGULA, E.; BARBOSA, A. C. A.; BARUFFI, M. M.; MONTAGNINI, R. C.; Níveis do Planejamento de Ensino. In: VAGULA, Edilaine; BARBOSA, Ana Clarisse Alencar; BARUFFI, Mônica Maria; MONTAGNINI, Rosely Cardoso. (orgs.). Didática. $1^{\underline{a}}$ ed. Londrina: Editora e Distribuidora Educacional S.A., 2014, v. 1, p. 2-184.

VEIGA, I. P. A. Inovações e projeto político-pedagógico: uma relação regulatória ou emancipatória? Cad. Cedes, Campinas, v. 23, n. 61, p. 267-281, dez. 2003. Disponível em: <http://www.cedes.unicamp.br>. Acesso em 06 de dez. de 2017.

REZENDE, V. M. Descentralização ou desconcentração? O controle dos gastos com a educação: ação que supera a autonomia da escola. 28 $8^{\text {a }}$ Reunião da ANPEd, 2005. Disponível em: <http://28reuniao.anped.org.br/gt05.htm>. Acesso em: 25 de jan. 2018.

Recebido em fevereiro 2019

Aprovado em abril 2019 